\title{
Discapacidad y Observaciones Generales de los comités de derechos humanos de la ONU: una relación asimétrica entre la invisibilidad, el modelo médico y el modelo de derechos humanos
}

\section{Disability and General Recommendations of UN human rights committees: An asymmetric relationship between invisibility, medical model and human rights model}

\begin{abstract}
Resumen
Este artículo pretende determinar el nivel de inclusión de la discapacidad en las Observaciones Generales de los comités de Naciones Unidas, y si esta incorporación se produce desde una perspectiva de derechos humanos. La metodología se ha centrado en realizar un análisis crítico y emancipatorio. En particular, se investiga el tratamiento de la discapacidad (si la inclusión es sectorial o transversal, la definición de discriminación por discapacidad y el modelo de discapacidad asumido) y se establecen comparaciones con otros colectivos excluidos. El análisis permite evidenciar el diferente nivel de compromiso con la discapacidad, el tratamiento asimétrico de ésta y las carencias en entender la discapacidad como una cuestión de derechos humanos. La conclusión principal es la necesidad de que la Convención sobre los Derechos de las Personas con Discapacidad se convierta en un marco obligatorio y expansivo.
\end{abstract}

\section{Palabras clave}

Observaciones Generales,

discapacidad, discriminación, modelo médico, modelo social, modelo de derechos humanos, comités de derechos humanos, Naciones Unidas.

\begin{abstract}
The purpose of this article is to determine the level of inclusion of Disability in the UN Committees General Comments, and if this is done from a human rights perspective. The methodology used focuses on a critical and emancipatory analysis. In particular investigated the different approached used (mainstreaming or specific treatment, discrimination definition, disability model used) and it also compares with other excluded groups. The analysis allows to show different level of commitment with disability, the asymmetric treatment, the lacks in understanding disability as a human rights issue. The main finding is the need of a compulsory expansion of the Convention of the rights of persons with disabilities.
\end{abstract}

\section{Keywords}

General Comments, disability, discrimination, medical model, social model, human rights model, human rights committees, United Nations.

\section{Leonor Lidón Heras \\ <llidon@feacem.es>}

Federación Empresarial Española de Asociaciones de Centros Especiales de Empleo (FEACEM)

\author{
Para citar: \\ Lidón Heras, L. (20I3): "Discapacidad \\ y Observaciones Generales de los \\ comités de derechos humanos de la \\ ONU: una relación asimétrica entre la \\ invisibilidad, el modelo médico y \\ el modelo de derechos humanos", \\ Revista Española de Discapacidad, \\ I (I): 47-72. \\ doi: <http://dx.doi.org/I0.5569/234O- \\ 5IO4.OI.OI.03>
}

Fecha de recepción: 7-I I-2OI 2 Fecha de aceptación: 22-4-20I3 


\section{Introducción}

La relación entre discapacidad, derechos humanos y Naciones Unidas no se concreta, en forma de tratado internacional, hasta el siglo XXI. Con anterioridad, el único tratado de derechos humanos que la había visibilizado fue la Convención Internacional del Niño; el resto de tratados, al hablar de discriminación y colectivos vulnerados, silencian al de las personas con discapacidad ${ }^{\mathrm{T}}$, que quedaba teóricamente incluido en el amplio e indeterminado genérico de "cualquier otra condición social". Pero la realidad demostró que el sistema internacional de tratados no sólo era insuficiente para proteger y garantizar el ejercicio de sus derechos humanos (Quinn y Degener, 2002: I), sino que las personas con discapacidad estaban sujetas a continuas violaciones de sus derechos (VV.AA., 2007: I).

Esta distancia entre teoría y realidad se explica desde la invisibilidad social de las personas con discapacidad, que se refleja jurídicamente. Así, su no inclusión explícita en los tratados internacionales de derechos humanos es una clara manifestación de esta afirmación. Esta indiferencia de la comunidad internacional al reconocimiento de sus derechos empieza a cambiar con la aprobación, en 2006, de la Convención de Derechos de las Personas con Discapacidad (CDPD). Pero éste es un punto de inflexión que tiene muchos retos por delante, entre otros, propiciar y reforzar un cambio de paradigma en la forma de entender la discapacidad en el sistema internacional de tratados.

A lo largo de la historia de Naciones Unidas han existido -y coexisten hoy día- diferentes modelos que explican cómo debe ser entendida y, por tanto, tratada la discapacidad. En este artículo se van a referenciar los $\operatorname{dos}^{2}$ que se

I. En este artículo se hablará de discapacidad de forma genérica, no diferenciándose entre deficiencia como dimensión biológica, y discapacidad como la interacción entre la deficien cia y la barrera, que es la definición dada por la Convención de Derechos de las Personas con Discapacidad.

2. Existen discusiones doctrinales en cuanto a la denominación y sus implicaciones. No se trasladan al texto, pues no es el objeto de este artículo. entienden claves para situar las contradicciones que existen y que se expresan en las diferentes plasmaciones en las Observaciones Generales (OO.GG.): el modelo médico, y el modelo social o de derechos humanos de la discapacidad.

El modelo médico de la discapacidad se asienta en una perspectiva individualista y sociosanitaria. Asume que la exclusión social de la persona con discapacidad es una consecuencia lógica de su situación, es decir, de sus limitaciones, por lo que es un problema de y para la persona. La traducción jurídica de esta concepción es que son tratados desde la perspectiva de la salud y lo asistencial, pero no desde el reconocimiento de sus derechos en clave de equiparación con los demás.

Frente a este modelo, el modelo social rechaza el determinismo biológico y denuncia que son los entornos, las fuerzas económicas, políticas y sociales y, por supuesto, las leyes las que discapacitan (Jones y Basser Marks, I999: 5). Este cambio de enfoque radical fue el que permitió la recatalogación de la discapacidad como una cuestión de derechos humanos (Degener, I999: I8I). El modelo social denuncia las barreras y sus efectos de exclusión, y reivindica que la sociedad se haga inclusiva y se afirme desde la equiparación de oportunidades y la igual dignidad y valor de todas las personas. Jurídicamente implica el reconocimiento en clave de igualdad de todos los derechos, y el establecimiento de las garantías y mecanismos para hacerlos efectivos; además, supone la transversalización y visibilización de la discapacidad en todos los ámbitos.

La CDPD, si bien se basa en el modelo social, crea un marco de derechos humanos, y así, permite que las barreras puedan ser identificadas como violaciones a los derechos humanos (Trömel, 20Io). Por ello, hablar de modelo de derechos humanos implica un refuerzo jurídico de incuestionable valor y de gran potencialidad que sobrepasa al modelo social ${ }^{3}$.

3. Por ello, en este artículo, una vez explicados las principales implicaciones de cada modelo, se hablará de modelo de derechos humanos. 
Pero este tratado internacional no es un punto de llegada, sino de salida, que aplica a los Estados partes, pero también a Naciones Unidas y, por tanto, a todos sus comités de derechos humanos de los diferentes tratados, que deben aplicar el modelo de derechos humanos de la discapacidad en sus Observaciones Generales (OO.GG.).

Sin embargo, a lo largo del análisis se mostrará que se cuelan concepciones, incluso después de la aprobación de la CDPD, que confieren distinto valor a las personas y a sus derechos cuando concurre la circunstancia de la discapacidad (especialmente a través de la modulación de derechos). Y lo que es mucho más grave aún: perdura la invisibilidad de este colectivo.

El artículo, tras definir y significar la importancia de las OO.GG., hace un análisis doble:

- Cuantitativo: número de OO.GG., si incluyen o no de la discapacidad y si es de forma sectorial o transversal; también se hacen comparaciones, en términos de ser referenciados, con otros grupos excluidos.

- Cualitativo: analiza el modelo de la discapacidad, el concepto de discriminación por motivo de discapacidad, el concepto y contenido de la accesibilidad, la discapacidad como cuestión que se ha de defender o como cuestión que se ha de prevenir, y si trata la discapacidad como un todo o atendiendo a su diversidad.

Dentro del análisis de las OO.GG. de cada comité4, se ha optado por una descripción cronológica que tiene dos puntos de inflexión: si existe una Observación General dedicada a la discapacidad (no aplicable a todos) y la aprobación de la CDPD ${ }^{5}$.

4. No se incluye el Comité de los Derechos de las Personas con Discapacidad.

5. El artículo incluye, en un anexo, un listado con las Observaciones Generales de los diferentes comités de derechos humanos.

\section{Tratados de derechos humanos y Observaciones Generales}

La realidad ha demostrado que la implementación de los diferentes tratados de derechos humanos requiere de pautas que guíen este proceso. Para ello, los distintos comités de los diferentes tratados de derechos humanos elaboran Observaciones Generales que están dirigidas a facilitar la aplicación y protección de los derechos contenidos en el tratado correspondiente. Así, entre otras, establecen pautas de interpretación o clarificación y definición de conceptos. Su importancia radica en que crean un cuerpo jurídico universal y vivo en materia de derechos humanos. Por ello, es esencial una coherencia y unicidad entre ellos que, en materia de discapacidad, no se produce.

\section{Observaciones Generales del Comité de Derechos Humanos}

El Comité de Derechos Humanos (CCPR), que es el encargado de velar por el Pacto Internacional de Derechos Civiles y Políticos, de 1966, ha elaborado 34 Observaciones Generales ${ }^{6}$. Ninguna de ellas está dedicada de forma específica a la discapacidad, y tan sólo una la referencia de forma transversal. La Observación General n 25, de 1996, relativa a la participación en los asuntos públicos y el derecho de voto, establece que: a) no es razonable restringirlo por motivos de discapacidad física, pero sí en caso de incapacidad mental; y que b) la asistencia que se preste para su ejercicio a los discapacitados, los ciegos o los analfabetos deberá tener carácter independiente. Pero no profundiza más y, de

6. La mayor consistencia terminológica en relación con la discapacidad aconsejó que, finalmente, las consultas se hicieran, con alguna excepción, sobre los textos originales en inglés. Las referencias a las distintas OO.GG. están hechas según el idioma consultado, aunque en algunas de ellas se compararon la versión castellana e inglesa. 
hecho, no incluye la discapacidad en el apartado relativo a la cláusula de no discriminación, aunque está en línea con su asunción de que es causa objetiva y razonable denegar el derecho a las personas con incapacidad mental. En este sentido, reproduce y se contagia del tratamiento que da la Observación General $n^{\circ}$ I 8 , de I989, sobre no discriminación, que no explicita la prohibición de discriminación por motivo de discapacidad, por lo que la discapacidad deberá entenderse incluida en la cláusula genérica de "cualquier otra condición social".

Las tres OO.GG. aprobadas tras la CDPD mantienen invisible la discapacidad.

\section{Observaciones Generales del Comité de Derechos Económicos, Sociales y Culturales}

El Comité de Derechos Económicos, Sociales y Culturales (CESCR) es el encargado de velar por el Pacto Internacional de Derechos Económicos, Sociales y Culturales, de I966. La relación entre el comité y la discapacidad ha tenido reflejo a lo largo de sus 2I Observaciones: la n ${ }^{\circ}$, de I994, es exclusiva para las personas con discapacidad, y la discapacidad es tratada transversalmente en doce OO.GG.

La primera que la incluye lo hace de forma transversal: la Observación General $n^{\circ} 4: \mathrm{el}$ derecho a una vivienda adecuada manifiesta, en relación a este derecho, que debe garantizarse cierto grado de consideración con respecto a grupos desfavorecidos, como los mayores, los niños o las personas con discapacidad.

El tratamiento sectorial llega con la Observación General $n^{\circ}$ 5, de I994, relativa a discapacidad. Con esta Observación, el CESCR establece las líneas maestras de las obligaciones de los Estados en materia de discapacidad que impone el citado Pacto, toda vez que manifiesta su preocupación por que estos derechos apenas se incluyen en sus informes.
La Observación $n^{\circ}$ 5: personas con discapacidad es ambivalente, ya que asume la definición de discapacidad conforme al modelo médico, pero aporta aspectos del modelo de derechos humanos. Su definición de discapacidad es conforme al modelo médico, al vincular falta de acceso a derechos con la discapacidad, y en este sentido, conmina a los Estados Partes a adoptar medidas, de conformidad a sus recursos, para que estas personas puedan superar los inconvenientes, en términos del disfrute de los derechos, derivados de su discapacidad. Sin embargo, su concepto de igualdad y no discriminación está escrito desde el modelo de derechos humanos. Por ello, a los efectos del Pacto establece que la discriminación por motivos de discapacidad es cualquier acto, incluida la denegación de ajustes razonables, que anule o dificulte el ejercicio de los derechos reconocidos en el Pacto, por lo que, en las medidas que adopten, deberán tenerse en cuenta las necesidades de las personas con discapacidad y garantizar su acceso a la participación y a los servicios en igualdad de condiciones. Además, para reforzar este aspecto, recuerda que el Programa de Acción Mundial para las Personas con Discapacidad afirma que todas las necesidades tienen la misma importancia y deben cubrirse orientándose por el principio de igualdad de oportunidades, y que las Normas Uniformes sobre la Igualdad de Oportunidades para las Personas con Discapacidad son una guía para interpretar el Pacto Derechos Económicos, Sociales y Culturales.

El CESCR hace una relectura de cada uno de los derechos contenidos en el Pacto a la luz de la discapacidad y desde la equiparación, por lo que actualiza el significado de las obligaciones de los Estados Partes en virtud de aquel en materia de discapacidad, y a tal fin establece que deberán revisar su legislación con una doble finalidad:

- Prevenir y erradicar la discriminación, derogando la que tenga contenido discriminatorio y promulgando legislación antidiscriminatoria.

- Adoptar medidas de acción positiva para reducir desventajas estructurales de cara a lograr la plena participación e igualdad de las personas con discapacidad. 
Precisamente, a partir de esta Observación se produce casi de forma constante, pero desigual, un tratamiento transversal de la discapacidad en el resto de Observaciones Generales.

La Observación General $n^{\circ}$ 6: los derechos económicos, sociales y culturales de las personas mayores recuerda que los Principios de las Naciones Unidas en Favor de las Personas de Edad afirman la dignidad de las personas mayores y su derecho a vivir con seguridad e integridad, con independencia de cualquier circunstancia, tal como edad, sexo, raza o discapacidad. Insiste en la necesidad de luchar contra los estereotipos negativos sobre las personas mayores que las muestran como personas incapaces, sin valor o como discapacitadas. Esta referencia ejemplifica la sutilidad con la que operan los prejuicios en torno a la discapacidad, pues primero la trata como circunstancia que hay que proteger, y después, de forma negativa, al prevenir que los mayores no sean mirados bajo el prisma de personas con discapacidad. En esta misma línea, en relación con el derecho a gozar del progreso científico y de sus aplicaciones, anima a los Estados a promover investigaciones que prevengan la aparición de enfermedades crónicas o discapacidades.

La Observación General $n^{\circ}$ I 2: el derecho a una alimentación adecuada reclama la accesibilidad a los alimentos para diferentes grupos, entre otros, las personas con discapacidad. Sin embargo, no da contenido a qué significa accesibilidad en este caso concreto.

La Observación General $n^{\circ}$ I3: el derecho a la educación establece que el acceso a ésta debe garantizarse bajo el principio de igualdad y no discriminación para todos los colectivos, entre los que incluye a las personas con discapacidad, y aboga, conforme a la Observación General $n^{\circ} 5$ : las personas con discapacidad, por la educación inclusiva y la formación adecuada de los profesores y maestros, y por la dotación de recursos necesarios.

La Observación General no I4: el derecho al disfrute del más alto nivel posible de salud incluye, entre los tratamientos de salud, aquellos que sean precisos para atender lesiones y discapacidades frecuentes, y en lo relativo a los destinatarios, señala que a los niños con discapacidades se les debe garantizar una vida decente y la participación en comunidad. En cuanto a la no discriminación de las personas con discapacidad, por un lado, afirma el principio de igualdad y no discriminación, subrayando que obliga tanto al sistema público de salud como a cualquier establecimiento privado, y, por otro lado, establece que es necesario que los edificios sean accesibles para las personas con discapacidad.

La Observación General $n^{\circ}$ I 5 : el derecho al agua marca las condiciones de ejercicio de este derecho bajo los principios de igualdad y no discriminación de ningún colectivo, entre los que enumera a las personas con discapacidad.

La Observación General $n^{\circ}$ I 6: la igualdad de derechos del hombre y la mujer al disfrute de los derechos económicos, sociales y culturales recuerda que las mujeres pueden sufrir doble discriminación, al unir a su condición de mujeres otros factores de exclusión, como la discapacidad.

La Observación General $n^{\circ}$ I7: el derecho de toda persona a beneficiarse de la protección de los intereses morales y materiales que le correspondan por razón de las producciones cientificas, literarias o artísticas de que sea autor(a) establece que dicho acceso debe cumplir cuatro características, entre ellas, a) la accesibilidad física de los tribunales y demás entidades encargadas de la protección de intereses morales y materiales que correspondan a todos los autores, incluso los autores con discapacidad; y b) la accesibilidad de la información, que debe ser comprensible para todos y publicada en los idiomas de las minorías lingüísticas. En el caso de la discapacidad, la accesibilidad se contempla desde la dimensión física de los entornos donde debe quedar amparada, mientras que la accesibilidad a la comunicación no tiene en cuenta de forma expresa la discapacidad, salvo que la fórmula "comprensible para todos" incluya formatos alternativos. 
La Observación General $n^{\circ}$ I 8: el derecho al trabajo asienta diferentes elementos interdependientes del derecho al trabajo, como la disponibilidad, la aceptabilidad, la calidad y la accesibilidad. Esta última es afirmada, además, sobre la igualdad y no discriminación por ninguna circunstancia, entre las que se inscribe la discapacidad.

El acceso a la seguridad social viene reflejado en la Observación General n ${ }^{\circ}$ I9, de 2008 , fecha en que ya había sido aprobada la CDPD. La Observación señala que los sistemas de previsión social deben proteger las situaciones de falta de ingresos debidas, entre otras, la enfermedad, la maternidad o la discapacidad. En cuanto a las prestaciones, además de cumplir criterios como cobertura, asequibilidad e información, también contempla la accesibilidad física de los servicios para las personas con discapacidad. Además, este derecho debe complementarse con la prestación de servicios sociales de rehabilitación para personas con enfermedades o discapacidad. En el ámbito del principio de la igualdad y no discriminación, los Estados, además de garantizar este derecho, deben aplicarlo, entre otros, a las personas con discapacidad mujeres, desempleados, desplazaos, niños o repatriados.

La Observación General $n^{\circ}$ 20: la no discriminación y los derechos económicos, sociales $y$ culturales, al tratar el acceso a este derecho, además de contemplar la discapacidad en lo relativo a igualdad, hace un exhaustivo análisis de los tipos de discriminación y de las acciones que deben desarrollar los Estados para erradicarla. Sin embargo, no incorpora ni la definición de discriminación por razón de discapacidad, ni la necesidad de aplicar la accesibilidad ni el diseño para todos. De hecho, confunde accesibilidad con ajustes razonables, al describir que se produce discriminación por la denegación de ajustes razonables en los entornos públicos y privados, en la medida en que son construidos de forma inaccesible para los usuarios de sillas de ruedas. Precisamente respecto a estos entornos debería exigir la accesibilidad, y si ésta fuera insuficiente, sería cuando deberían operar los ajustes razonables, como respuesta específica, y no genérica, como es en el caso que plantea.
En la Observación General n ${ }^{\circ} 2$ : derecho de toda persona a participar en la vida cultural, sigue en la misma línea en relación con la accesibilidad. Por un lado, reconoce que uno de los elementos del derecho a la participación en la vida cultural es la accesibilidad entendida como acceso de las personas con discapacidad. Sin embargo, no lo contempla como criterio que se ha de cumplir en los entornos, bienes y servicios, sino que lo indica como algo conveniente. Además, en el ámbito de la no discriminación en el derecho a tomar parte de la vida cultural no identifica a las personas con discapacidad como colectivo, que quedan, una vez más, bajo el genérico de "cualquier otra condición". En definitiva, no establece la relación entre no accesibilidad y falta de acceso a derechos.

Las OO.GG. del CESCR indican que este organismo es uno de los más activos en temas relacionados con la discapacidad, tanto por la extensa Observación específica que relee los derechos del Pacto Internacional de Derechos Económicos, Sociales y Culturales desde la equiparación, como porque se muestra permeable y receptivo al trabajo de Naciones Unidas en materia de discapacidad, y porque, desde un plano práctico, establece un estándar de cumplimiento a los Estados Partes y una referencia obligada para el resto de Observaciones, que encuentran en el CESCR una pauta de abordaje de la discapacidad.

Sin embargo, entre sus limitaciones se encuentra que el tratamiento que se hace no es siempre sistemático, y oscila entre el modelo médico y el social; y que se producen confusiones, especialmente en el ámbito del contenido de la accesibilidad como puesta a disposición y accesibilidad como criterio que han de cumplir los entornos, productos y servicios para que puedan ser disfrutados por las personas con discapacidad en igualdad de condiciones. Esa dicotomía entre prevención de la discapacidad y tratamiento de la discapacidad se produce también en los ámbitos referidos a salud.

Por otra parte, una vez aprobada la CDPD resulta extraña que la obvie y que no incida más en la relación entre discriminación (concepto 
que incluso decae), discapacidad, ajustes razonables y accesibilidad.

\section{Observaciones Generales del Comité para la Eliminación de la Discriminación Racial}

El Comité para la Eliminación de la Discriminación Racial es el encargado de velar por la Convención Internacional sobre la Eliminación de Todas las Formas de Discriminación Racial, de I965, y en ninguna de sus 34 Observaciones Generales ha prestado atención a la discapacidad, pese a que tres de ellas son posteriores a la CDPD.

\section{Observaciones Generales del Comité para la Eliminación de la Discriminación contra la Mujer}

El Comité para la Eliminación de la Discriminación contra la Mujer (CEDAW), que es el encargado de velar por la Convención sobre la Eliminación de Todas las Formas de Discriminación contra la Mujer, de I979, ha elaborado 29 Observaciones Generales, de las cuales una es relativa a discapacidad y en otras cuatro la incluye transversalmente.

\section{La Observación General $n^{\circ}$ I 8: mujeres con} discapacidad parte de dos premisas: que apenas hay información sobre mujer y discapacidad en los informes de los Estados, y que sobre las mujeres con discapacidad pesa doble discriminación. Por ello, recomienda que las medidas especiales que hayan adoptado para tratar su singularidad y, especialmente, garantizar el principio de igualdad de oportunidades en las áreas de educación, empleo, salud, seguridad social y en el acceso a la vida social y cultural incluyan información sobre las mujeres con discapacidad. Comparada con la Observación
General $n^{\circ} 5$ del CESCR, que hacía una relectura de los derechos económicos y sociales a luz de la discapacidad, es muy somera y no aporta cuestiones cualitativas ni intersectoriales entre género y discapacidad, ni tan siquiera avanza un concepto de discriminación, por lo que se entiende el menor efecto de esta Observación General en las posteriores aprobadas por el CEDAW.

Así, es muy significativo que ninguna de las dos Observaciones Generales dedicadas a la violencia contra la mujer incluya nada sobre mujer y discapacidad. Sin embargo, y dentro del ámbito de la violencia contra las mujeres mayores, la Observación General $n^{\circ}$ 27, sobre mujeres de edad, de 20Io, sí afirma que los Estados deberán promulgar leyes que prohíban la violencia contra mujeres mayores con discapacidad.

\section{La Observación General $n^{\circ}$ 24: salud y mujer} hace un tratamiento dual de la discapacidad: como derecho de las mujeres con discapacidad al acceso a la salud y a la provisión de las medidas específicas que requiera, y como una cuestión de salud pública que se ha de prevenir.

\section{La Observación General no 25: medidas} especiales de carácter temporal (párrafo I del artículo 4 de la Convención sobre la Eliminación de Todas las Formas de Discriminación contra la Mujer) plantea que, en los casos en los que pueda producirse múltiple discriminación, como por motivo de discapacidad, puede ser necesario que los Estados Partes adopten medidas específicas para eliminar la discriminación múltiple.

La Observación General $n^{\circ}$ 27: mujeres de edad y la protección de sus derechos humanos, aprobada tras la CDPD, trata la discapacidad en algunos de sus puntos, como en lo relativo a factores multidimensionales, o el mayor peso de los estereotipos cuando se es mujer y se tiene discapacidad; además trata áreas de mayor preocupación en el caso de mujer y discapacidad, como el acceso a la educación, al empleo, a la protección social, la accesibilidad de la información relativa a sus derechos, el acceso a la salud, la prevención de la violencia y el derecho al consentimiento libre e informado. 
La Observación General $n^{\circ} 28$ determina el alcance y significado del art. 2 de la Convención sobre la Eliminación de todas las Formas de Discriminación contra la Mujer, centrado en eliminar cualquier forma de discriminación contra la mujer, para lo cual establece que su lectura debe hacerse de forma holística y vinculada con las Observaciones Generales, las conclusiones de los informes del comité a los Estados Partes, las opiniones y demás literatura del comité, además de referirse a la CDPD. Sin embargo, y pese a reconocer que refugiadas, lesbianas o viudas son más vulnerables a la discriminación en las leyes civiles y penales, no incluye la discapacidad junto a otros factores -como raza, origen, religión, salud o estatus- en el tratamiento de la discriminación múltiple; es más, no deja abierto ningún genérico como “cualquier otra condición social”.

Es interesante hacer notar que la Observación General $n^{\circ} 29$, relativa a las consecuencias económicas del matrimonio, la familia y su disolución, no menciona a las mujeres con discapacidad. Es preocupante este silencio, pues aquí no hay remisiones a la CDPD, y perpetúa la invisibilidad de la mujer con discapacidad en relación al matrimonio y la familia y su disolución.

La dimensión que este comité ha dado a la mujer con discapacidad es, como se ha visto, muy menor, tanto por el contenido de Observación General $n^{\circ}$ I 8 específica sobre esta realidad, como por el resto de las OO.GG., que incluyen la discapacidad de forma transversal. No hay una definición de discriminación, ni una profundización seria en discriminación múltiple. No hay una perspectiva de derechos humanos, mujer y discapacidad.

7. Observaciones Generales del Comité contra la Tortura

El Comité contra la Tortura (CAT) es el encargado de velar por Convención contra la Tortura y Otros Tratos o Penas Crueles,
Inhumanos o Degradantes, de I $984 . \mathrm{Ha}$ elaborado tres Observaciones Generales, de las cuales dos, aprobadas con posterioridad a la CDPD, se refieren a la discapacidad de forma transversal.

En su Observación General $n^{\circ}$ 2: aplicación del artículo 2 por los Estados Partes, les recuerda que son ellos los internacionalmente responsables y que deben prohibir, impedir y castigar los actos de tortura y los malos tratos en todas las situaciones de privación o de limitación de libertad, como por ejemplo, hospitales, escuelas o instituciones que atienden a niños, personas de edad, enfermos mentales o personas con discapacidad. Además, visibiliza como colectivo con mayor riesgo de sufrir torturas o trato degradante a las personas con discapacidad, entre otros.

La situación de institucionalización o mayor desvalimiento de algunas personas con determinadas discapacidades queda amparada por esta previsión, especialmente cuando muchos de estos servicios son prestados por entidades privadas. Por tanto, es una llamada de atención a los Estados y a las entidades privadas que operan en ellos.

Por su parte, la Observación General $n^{\circ} 3$, sobre la aplicación del artículo I4, relativo al derecho a reparación en caso de tortura, incluye la discapacidad en el contenido del derecho y en el acceso a él. Así, establece que la reparación debe atender a las causas estructurales de la infracción si estuvo causada por discriminación y, entre otras, cita a la discapacidad. La indemnización debe compensar los perjuicios resultantes del daño físico o mental causado, el lucro cesante debido a la discapacidad causada por la tortura o los malos tratos, y la pérdida de oportunidades, de empleo o de educación, entre otros. La rehabilitación debe orientarse a que la persona logre la máxima autonomía, independencia e inclusión y participación; además, prevé que puede entrañar ajustes en su entorno físico y social. Desde el punto de vista formal, los Estados Partes deben establecer mecanismos eficaces para presentar quejas y llevar a cabo investigaciones, lo que implica 
que deben ser conocidos por y 'accesibles' para, entre otras, las personas que estén en establecimientos psiquiátricos o pertenezcan a grupos vulnerables, incluidas las que tengan una capacidad de comunicación limitada. Conforme al principio de no discriminación, los Estados Partes han de cerciorarse de que se pueda recurrir fácilmente a la justicia y a los mecanismos para solicitar y obtener reparación y de que haya medidas positivas que aseguren que la reparación sea igualmente 'accesible"s para todos los colectivos, incluidas las personas con discapacidad. En el proceso, debe prevenirse la estigmatización o victimización por pertenencia a algún colectivo, como el de las personas discapacidad. Con respecto a la vigilancia y presentación de informes, los Estados Partes deben dar información, entre otras cuestiones, sobre los mecanismos de queja y sobre cómo se dan a conocer y están al alcance de todos, y proporcionar como datos desglosados por edad, género, lugar y presunta violación.

Comparando estas dos OO.GG., la primera incide en la mayor situación de vulnerabilidad de las personas con discapacidad ante actos de tortura, y esta segunda, relativa a la reparación, si bien incluye la discapacidad, lo hace de forma ambivalente. Por un lado, orienta la rehabilitación a la autonomía, la independencia y la inclusión, y hasta prevé adaptaciones de los entornos, abogando por un modelo de derechos humanos. Sin embargo, en el ámbito de los mecanismos de garantías procesales, es confuso el sentido que da a la accesibilidad y, por tanto, a los mecanismos que puedan garantizarla; y en la elaboración de informes, no se desglosa información que permita conocer la incidencia del maltrato en personas con discapacidad. Por otra parte, asume casi de forma natural que se producirá una pérdida de oportunidades, derivada de la discapacidad,

7. El texto en inglés habla de 'accesibilidad', mientras que el texto en castellano habla de 'estar al alcance de todos'. Esto refuerza la imprecisión terminológica de la accesibilidad y de las traducciones.

8. De nuevo, el texto en inglés habla de 'accesibilidad', mientras que el texto en castellano habla de 'estar al alcance de todos'. que debe compensarse, cuando la clave es que estas exclusiones no se produzcan, porque si se producen, estamos hablando de discriminación.

\section{Observaciones Generales del Comité de los Derechos del Niño}

El Comité sobre los Derechos del Niño (CRC), que se encarga de velar por la Convención sobre los Derechos del Niño, de I989', ha elaborado trece Observaciones Generales, de las cuales una está dedicada a los niños con discapacidad y once tratan ésta transversalmente. Además, cuenta con otras tres OO.GG. en proceso.

Ya en su primera OO.GG., relativa a la educación, el CRC trata la discapacidad, señalando que el desarrollo máximo del niño en la educación comprende a todos los niños, sin que pueda discriminarse a ninguno, por razón de sexo, sida o discapacidad.

\section{La Observación General $n^{\circ}$ 2: el rol de las} instituciones nacionales independientes de derechos humanos en la promoción y protección de los derechos del niño reconoce el importante papel de instituciones nacionales independientes para la promoción de los derechos de los niños contenidos en la citada Convención, y les insta para que sean accesibles desde el punto de vista geográfico y físico, y para que hagan llegar su labor a todos los niños, especialmente a los más vulnerables, entre los que incluye a los niños con discapacidad.

\section{La Observación General $n^{\circ}$ 3: el VIH/sida y los derechos del niño hace un planteamiento holístico, poniendo en relación todos los derechos (entre los que cita el 23, relativo a niños con discapacidad) que contiene la Convención sobre los Derechos del Niño,}

\footnotetext{
9. Es necesario recordar que éste es el primer tratado de derechos humanos que visibiliza la discapacidad, tanto en la no discriminación (art. 2) como en la existencia de un artículo específico dedicado a los niños con discapacidad (art. 23).
} 
remarcando que los Estados deben garantizar todos los derechos contenidos en el documento y aplicarlos sin discriminación, entre otras causas, por discapacidad. Refuerza la importancia de la comunicación y el diálogo sobre este tema en las escuelas y las familias, y apunta que los Estados Partes deben procurar que los mensajes de prevención sean adecuados al género, idioma o discapacidad. En cuanto al acceso a la salud, establece que debe garantizarse el principio de igualdad de todos los colectivos, entre los que incluye a los niños con discapacidad. Reconoce el riesgo de vulnerabilidad, violencia y discriminación múltiple cuando, además de sida, concurren otras circunstancias, como la discapacidad.

La Observación General $n^{\circ}$ 4: la salud y el desarrollo de los adolescentes en el contexto de la Convención sobre los Derechos del Niño establece el principio de igualdad y no discriminación de, entre otros, los adolescentes con discapacidad, para los que puedan ser necesarios mecanismos 'especiales' ${ }^{\text {ㅇ }} \mathrm{de}$ protección, por su mayor vulnerabilidad y riesgo de violencia, explotación y de menor acceso a la salud. Al tratar la educación de los adolescentes con discapacidad, además de referirse a una educación de calidad, afirma que ésta deberá desarrollarse siempre que se pueda en la escuela ordinaria, pero no establece mecanismos que la faciliten. Con respecto a la salud, recuerda que los adolescentes con discapacidad tienen el mismo derecho al más alto nivel posible de salud física y mental, el cual, entre otros aspectos, implica que los bienes y servicios sean accesibles, se atienda las necesidades relativas a su sexualidad y se eliminen los obstáculos que les impidan el ejercicio de sus derechos. La Observación muestra preocupación en el caso de las enfermedades mentales y prevé que los niños que las padecen sean tratados en su comunidad siempre que sea posible, y que la hospitalización o internamiento en establecimiento psiquiátrico debe adoptarse

Io. El texto en castellano e inglés hablan de 'especial' y no de 'específicas'. La noción de especificidad atiende mejor a las necesidades de las personas con discapacidad, toda vez que le da un matiz de adecuación y permanencia. En adelante, se hará este entrecomillado para señalarlo, pero no se incluirá en nota a pie de página. de conformidad con el principio del interés superior del niño; sin embargo, guarda silencio sobre la duración y sobre si puede producirse cuando el motivo es sólo la enfermedad mental. En cuanto a las causas de la discapacidad, señala a los accidentes de tráfico y recuerda que éstos son más comunes entre los adolescentes, por lo que insta a tomar medidas de educación vial. En su análisis de la violencia institucional hacia los adolescentes, establece que los Estados Partes deben tomar medidas para erradicarla en establecimientos tales como reformatorios o centros para personas con discapacidad. $\mathrm{Y}$ en cuanto a los datos, establece que en su recopilación debe incluirse a los adolescentes con discapacidad, entre otros colectivos.

En su Observación General $n^{\circ}$ 5: medidas generales de aplicación de la Convención sobre los Derechos del Niño (artículos 4 y 42, y párrafo 6 del artículo 44), el comité recuerda que la obligación de no discriminación incluye tanto adoptar medidas que garanticen los derechos como una actitud activa que identifique a los niños que puedan requerir medidas 'especiales' para el reconocimiento y efectividad de sus derechos, motivo por el que insiste en la toma de datos desagregada para permitir identificar incluso discriminaciones potenciales. En lo relativo a la accesibilidad, requiere a los Estados Partes que sus informes se presenten en formatos adecuados para las personas con discapacidad.

La Observación General no 6: trato de los menores no acompañados y separados de su familia fuera de su país de origen hace una relectura de todos los derechos de la Convención aplicada a los niños en esta situación. En cuanto al derecho a la educación de este colectivo, los Estados Partes deben asegurar el acceso a su formación y, en el caso de niños con necesidades 'especiales', en particular, los niños con discapacidad, debe garantizarles el acceso a la educación de calidad.

La Observación General $n^{\circ}$ 7: realización de los derechos del niño en la primera infancia, en el apartado relativo a no discriminación, establece que todos los derechos de la Convención son 
aplicables a todos los niños. Al carecer de definición de discriminación, recurre a numerosos ejemplos que pueden servir de guía: cuidados y atención insuficientes, menores oportunidades de juego, inhibición de la libre expresión de sentimientos y opiniones, e incluso trato rudo. Esta indefinición provoca que no considere y valore de forma idéntica la conculcación de derechos por motivo de discriminación, y así, la gradúa en función del colectivo afectado: a) en el caso de las niñas, la discriminación es considerada como una grave violación de derechos; b) a los niños con discapacidad, la discriminación les reduce sus perspectivas de supervivencia y su calidad de vida, por lo que recuerda que pueden requerir de asistencia adicional o 'especial' a fin de garantizar su integración y la realización de sus derechos; c) con respecto a los niños con sida, la discriminación les priva de la ayuda y el apoyo que más necesitan. Nótese que, pese a esta defensa y ejemplificación de cómo la discriminación afecta a estos colectivos, no la interpreta igual: sin duda, las niñas son las que reciben un trato más ligado a una perspectiva de derechos, ya que su discriminación la identifica como grave violación de derechos; sin embargo, para el resto de colectivos, no es así, y se centra en otro tipo de efectos. Este doble tratamiento no es entendible en un texto de derechos humanos y, en todos los casos, la discriminación constituye una gravísima violación de los derechos de la primera infancia. Entre los colectivos más vulnerables dentro de este grupo etario, identifica a los niños y niñas con discapacidad, que tienen más riesgo de no ser inscritos. Establece que estos niños no deberán ser institucionalizados por razón de discapacidad, lo que significa que les reconoce su derecho a vivir en comunidad, defiende su derecho a la salud y la educación, y además de proclamar su igualdad de derechos, reclama la atención a las necesidades 'especiales' que puedan tener.

La Observación General $n^{\circ}$ 9: los derechos de los niños con discapacidad, de 2006, coincide con las fases finales de aprobación de la CDPD. En esta Observación, se analizan los artículos 2 (no discriminación) y 23 (niños con discapacidad), para seguidamente abogar por la inclusión de los niños con discapacidad en la sociedad. Esta Observación asume la definición de discapacidad como sumatorio de deficiencia y barrera que se estaba negociando en el proyecto de Convención sobre los Derechos de las Personas con Discapacidad. Si bien asume que la discapacidad es la interacción entre deficiencia y barrera, es extraño que no defina el concepto de discriminación por razón de discapacidad, es decir, que identifique el efecto discapacitante de la barrera, pero no lo haga como causa de discriminación.

En el análisis del art. 2, ahonda en la situación de mayor discriminación de estos niños, enumerando todas las situaciones en las que se produce vulneración a través de la discriminación, toda vez que señala el peso de los estigmas y prejuicios. Por ello, conmina a los Estados Partes a eliminar toda forma de discriminación mediante normativa que la proscriba y permita denunciarla, y mediante el recurso a campañas de concienciación. Además, visibiliza la situación de mayor vulnerabilidad de las niñas con discapacidad. El análisis del art. 23, por su parte, está marcado por un objetivo esencial, la máxima inclusión del niño con discapacidad en la sociedad, y por la determinación de los apoyos y asistencia 'especiales' que pueda requerir el niño con discapacidad, especialmente en lo referido a educación, capacitación, servicios de salud, de rehabilitación, preparación para el empleo y actividades de esparcimiento.

El resto de la Observación relativa a niños con discapacidad va encaminada a dar pautas de actuación a los Estados Partes sobre medidas que han de adoptar, en las que, además, apunta principios generales, como el de no discriminación (que sigue sin definir) y el del interés superior del niño. En materia de accesibilidad, hace diferentes anotaciones: a) en lo relativo a medios de comunicación, recuerda la relación entre autonomía y posibilidad de acceder a aquellos; b) con respecto a los transportes e instalaciones públicas, establece que la falta de accesibilidad es motivo de exclusión y marginación, por lo que insta a que el transporte sea accesible y, en la medida de lo posible, gratuito; y c) en cuanto a las edificaciones, 
exhorta a que sean modificadas para hacerlas lo más accesibles posibles. Aunque se muestra preocupado al respecto, el comité asume que es posible la institucionalización de niños con discapacidad, por lo que da pautas sobre ella: que sea absolutamente necesaria y responda al interés superior del niño, y que el modelo de institución esté centrado en los derechos y las necesidades del niño. Lo que el CRC no dice es si asume que el motivo de institucionalización sea la discapacidad: aceptarlo sería discriminatorio, pero el CRC no define la discriminación por motivo de discapacidad.

Dentro del ámbito de la salud, incluye los aspectos relativos a cuidados generales y específicos, la prevención, la detección precoz o el tratamiento coordinado. En cuanto al coste, al igual que para el transporte, establece que deben prestarse de forma gratuita siempre que sea posible, pero no delimita si se refiere a la prestación del servicio en general o para el caso de los niños con discapacidad, máxime cuando este tipo de derecho son los denominados económicos, sociales y culturales de realización progresiva, según la capacidad de los Estados y hasta el máximo de sus recursos, pero en todo caso siempre desde la igualdad y no discriminación: es decir, no podría defenderse que para unos niños el coste sea gratuito y para otros no.

En cuanto a la educación, además de afirmar que gozan del mismo derecho, preconiza una educación gratuita e inclusiva. Y en lo relativo a contenidos, establece que la educación de un niño con discapacidad ha de orientarse a la potenciación de su autoestima, asegurando que se sienta respetado por los demás como ser humano, sin limitación alguna de su dignidad.

Asimismo, expresa con preocupación que los niños con discapacidad tienen mayor riesgo de ser explotados económica y sexualmente, así como que la exposición a situaciones complejas, como la guerra o la condición de refugiado, son causa de discapacidad.

Conforme se ha subrayado, esta Observación, pese a ser coetánea de la CDPD y asumirla en parte, carece de definición de discriminación por causa de discapacidad y, sin definición, no es posible hablar de modelo de derechos humanos. Por ello, dentro del espectro del modelo médico, se entendería que no termine de relacionar barrera con discriminación y se quede en el desiderátum de que los entornos sean accesibles.

El modelo médico se cuela en la percepción de la discapacidad como concepto incapacitante $y$, en bloque, en su tratamiento del deporte, donde asume que los niños con discapacidad difícilmente podrán competir con niños sin discapacidad, dadas las exigencias físicas del deporte, y defiende la existencia de juegos exclusivos para niños con discapacidad, para que puedan competir de forma equitativa y segura. Para contrarrestar esta afirmación, en las Tablas I y 2 se muestran las diferencias en marcas mundiales en dos deportes, roo metros lisos (atletismo) y roo metros libres (natación), para deportistas con y sin discapacidad. En algunos, las diferencias son mínimas, en otras, por el tipo de discapacidad, son mayores, pero sin duda cuestionan el paternalismo de la Observación del comité.

Los datos muestran que el CRC ha obviado el crisol de la discapacidad. Por tanto, un niño con una discapacidad sensorial puede competir, y un niño con otro tipo de discapacidad podría competir también con un ajuste razonable; es más, que hicieran deporte juntos reforzaría, más allá de la competición, los valores del esfuerzo y la superación, iguales para cualquier deportista, para cualquier ser humano. Si se lleva el planteamiento del CRC del plano físico al cognitivo, podría concluirse que, 'dada su menor capacidad cognitiva', los niños con discapacidad deben estar en aulas exclusivas y no bajo un modelo inclusivo. En definitiva, el CRC ha reflejado prejuicios de menor capacidad y de tratar la discapacidad como un todo, sin atender su diversidad.

Sin embargo esta Observación también contiene importantes aportaciones desde el modelo de derechos humanos. Por un lado, subraya, con las limitaciones mencionadas, la importancia de la accesibilidad del transporte y los entornos públicos (inédito para la Convención sobre los 
Tabla 1. Récords del mundo en 100 metros lisos. Clasificación de atletas con discapacidad frente al mejor atleta sin discapacidad

\begin{tabular}{|c|c|c|c|c|}
\hline & Nombre y apellido & Año & Marca & $\begin{array}{l}\text { Diferencia con récord mundial } \\
\text { de atleta sin discapacidad }\end{array}$ \\
\hline Atleta sin discapacidad & Usain Wolt & 2009 & 0:09:58 & - \\
\hline \multicolumn{5}{|c|}{ Atleta con discapacidad (clasificación) } \\
\hline $\begin{array}{l}\text { T13 } \\
\text { (deficiencias visuales } \\
\text { leves) }\end{array}$ & Jason Smyth & 2012 & 0:10:46 & 0:00:88 \\
\hline $\begin{array}{l}\text { T46 } \\
\text { (discapacidad física en un } \\
\text { brazo) }\end{array}$ & Ajibola Adeoye & 2012 & 0:10:72 & 0:01:14 \\
\hline $\begin{array}{l}\text { T38 } \\
\text { (parálisis cerebrales leves) }\end{array}$ & Evan O'Hanlon & 2012 & 0:10:79 & 0:01:21 \\
\hline $\begin{array}{l}\text { T44 } \\
\text { (discapacidad física en } \\
\text { extremidades inferiores) }\end{array}$ & Jonnie Peacock & 2012 & 0:10:85 & 0:01:27 \\
\hline \multirow{2}{*}{$\begin{array}{l}\text { T43 } \\
\text { (discapacidad física en } \\
\text { extremidades inferiores) }\end{array}$} & Oscar Pistorius & 2007 & \multirow{2}{*}{ 0:10:91 } & \multirow{2}{*}{ 0:01:33 } \\
\hline & Blake Leeper & 2012 & & \\
\hline $\begin{array}{l}\text { T45 } \\
\text { (discapacidad física en } \\
\text { dos brazos) }\end{array}$ & $\begin{array}{l}\text { Yohansson } \\
\text { Nascimento }\end{array}$ & 2012 & 0:10:94 & 0:01:36 \\
\hline $\begin{array}{l}\text { T11 } \\
\text { (ciegos totales) }\end{array}$ & Lucas Prado & 2008 & 0:11:03 & $0: 01: 45$ \\
\hline $\begin{array}{l}\text { T54 } \\
\text { (personas en silla ruedas } \\
\text { con discapacidades más } \\
\text { leves) }\end{array}$ & Leo Pekka Tahti & 2012 & 0:13:63 & 0:04:05 \\
\hline
\end{tabular}

Fuente: Elaboración propia a partir de datos facilitados por el Comité Paralímpico Español. 
Tabla 2. Récords del mundo en 100 metros libres. Clasificación de nadadores con discapacidad frente al mejor nadador sin discapacidad

\begin{tabular}{|c|c|c|c|c|}
\hline & & & & \\
\hline & Nombre y apellido & Año & Marca & $\begin{array}{l}\text { Diferencia con récord } \\
\text { mundial de nadador } \\
\text { sin discapacidad }\end{array}$ \\
\hline Nadador sin discapacidad & César Cielo & 2009 & $0: 46: 91$ & - \\
\hline Nadador con discapacidad & sificación) & & & \\
\hline $\begin{array}{l}\text { S10 } \\
\text { (discapacidad física o } \\
\text { parálisis cerebrales más } \\
\text { leves) }\end{array}$ & Andre Brasil & 2010 & $0: 50: 87$ & 0:03:96 \\
\hline $\begin{array}{l}\mathrm{S} 12 \\
\text { (deficiencias visuales } \\
\text { severas) }\end{array}$ & Maksym Veraksa & 2009 & 0:50:91 & 0:04:00 \\
\hline $\begin{array}{l}\mathrm{S} 13 \\
\text { (deficiencias visuales leves) }\end{array}$ & Ihar Boki & 2012 & $0: 51: 91$ & 0:05:00 \\
\hline $\begin{array}{l}\text { S9 } \\
\text { (discapacidad física o } \\
\text { parálisis cerebral) }\end{array}$ & Matthew Cowdrey & 2008 & $0: 55: 30$ & 0:08:39 \\
\hline $\begin{array}{l}\text { S8 } \\
\text { (discapacidad física o } \\
\text { parálisis cerebral) }\end{array}$ & Yinan Wang & 2012 & $0: 56: 58$ & 0:09:67 \\
\hline $\begin{array}{l}\text { S11 } \\
\text { (ciegos totales) }\end{array}$ & John Morgan & 1986 & 0:56:67 & 0:09:76 \\
\hline $\begin{array}{l}\text { S7 } \\
\text { (discapacidad física o } \\
\text { parálisis cerebral) }\end{array}$ & David Roberts & 2012 & 1:00:34 & $0: 13: 43$ \\
\hline $\begin{array}{l}\text { S6 } \\
\text { (discapacidad física o } \\
\text { parálisis cerebral) }\end{array}$ & Anders Olsson & 2009 & $1: 05: 45$ & $0: 18: 54$ \\
\hline $\begin{array}{l}\text { S5 } \\
\text { (discapacidad física o } \\
\text { parálisis cerebral) }\end{array}$ & Daniel Dias & 2012 & 1:08:39 & $0: 21: 48$ \\
\hline $\begin{array}{l}\text { S4 } \\
\text { (discapacidad física o } \\
\text { parálisis cerebral) }\end{array}$ & Richard Oribe & 2009 & $1: 22: 43$ & $0: 35: 52$ \\
\hline $\begin{array}{l}\text { S3 } \\
\text { (discapacidad física o } \\
\text { parálisis cerebral) }\end{array}$ & Dmytro Vynohradets & 2010 & $1: 34: 02$ & $0: 47: 11$ \\
\hline $\begin{array}{l}\text { S2 } \\
\text { (discapacidad física o } \\
\text { parálisis cerebral) }\end{array}$ & Yang Yang & 2012 & 2:03:71 & $1: 16: 80$ \\
\hline $\begin{array}{l}\text { S1 } \\
\text { (discapacidad física o } \\
\text { parálisis cerebrales más } \\
\text { severas) }\end{array}$ & Itzhak Mamistvalov & 2012 & $2: 15: 83$ & 1:28:92 \\
\hline
\end{tabular}

Fuente: Elaboración propia a partir de datos facilitados por el Comité Paralímpico Español. 
Derechos del Niño) y además afirma derechos importantes, como el empleo y su relación con la formación, la capacitación para atender las especificidades derivadas de la discapacidad y, muy especialmente, el de vivir en comunidad con acceso a todos los derechos, cuestión que queda insuficientemente protegida, por esa ambivalencia entre los modelos de discapacidad y la falta de definición del concepto de igualdad y no discriminación en materia de discapacidad.

La inclusión de la discapacidad en las OO.GG. es prolija tras la aprobación de la $\mathrm{n}^{\circ} 9$ y la CDPD, pero las Observaciones siguen moviéndose entre el modelo médico y el de derechos humanos.

La Observación General no Io: derechos del niño en la justicia de menores expresa las carencias en este ámbito y, especialmente, en materia de derechos procesales, aplicación de medidas extrajudiciales y privación de libertad. En concreto, recuerda que el sistema debe estar basado en el principio de igualdad y no discriminación y que, conforme a éste, se debe prestar especial atención a las desigualdades de hecho que pueden afectar a determinados grupos vulnerables, como niños de la calle, de minorías étnicas o religiosas, o niños con discapacidad. Por ello, insta a los Estados Partes a capacitar a los profesionales que intervienen y garantizar, mediante normas o protocolos, el principio de igualdad de trato. En la configuración del juicio, que debe ser justo e imparcial, requiere que los profesionales que intervienen estén informadas sobre el desarrollo físico, psicológico, mental y social del niño, y, en particular, del adolescente, y que además tenga en cuenta las necesidades 'especiales' de los niños más vulnerables, entre otros, los niños con discapacidad, los desplazados, los niños de la calle o los refugiados.

La Observación explicita diferentes garantías, que no regula igual si concurre la discapacidad. Así, en lo referente al derecho a un intérprete para los niños que hablan otro idioma, establece que tienen derecho a contar con la asistencia gratuita de un intérprete, el cual deberá prestarse en todas las etapas del proceso; es más, el intérprete deberá estar capacitado para trabajar con niños; todo ello para garantizar que el niño comprenda cabalmente las preguntas que se le hagan y se facilite el ejercicio de su derecho a un juicio imparcial y a una participación efectiva. Sin embargo, y pese a tratarse del mismo derecho, el derecho a un juicio imparcial y una participación efectiva, para los niños con discapacidad, se diluye en una recomendación a los Estados Partes para que aseguren a estos niños una asistencia adecuada y efectiva mediante profesionales especializados. Como sucedía con la Observación General $n^{\circ}$ 9, se reproduce el efecto conculcatorio de la igualdad por la no definición de la discriminación por motivos de discapacidad. De nuevo se asume que su discapacidad es causa de su exclusión, y se regula con mayor tibieza y desde un enfoque asistencialista y no de derechos humanos.

La Observación General $n^{\circ}$ I I: los niños indígenas y sus derechos en virtud de la Convención, al establecer el principio de igualdad y no discriminación, insta a los Estados a que incluyan dicho principio en toda su normativa y adopten las medidas necesarias, incluidas las 'especiales' (para lo cual remite a su Observación General $n^{o} 5^{I I}$ sobre medidas generales de implantación de la Convención), por lo que deberá tener en cuenta los casos de múltiple discriminación, como pudiera ocurrir con las niñas indígenas o con los niños con discapacidad. De la relectura que hace de los derechos, el grupo de niños con discapacidad aparece reflejado en el acceso a la salud, pero no en el derecho a la educación o a la inscripción en el registro, y tampoco hay referencias a tales derechos en el caso de los niños en los conflictos armados y los niños refugiados, o la explotación económica o sexual, aspectos, sin embargo que, como se ha visto, se han incluido en otras Observaciones y que son olvidados en ésta. Estas asimetrías entre OO.GG. señalan los límites de atender la desigualdad desde un único ámbito y no valorar que los seres humanos son crisoles de circunstancias.

I I. Recordemos que esta Observación, en la aplicación del principio de igualdad y no discriminación, insta a los Estados a que "identifiquen activamente a los niños y grupos de niños cuando el reconocimiento y la efectividad de sus derechos pueda exigir la adopción de medidas especiales”. 
En la Observación General no I 2: el derecho del niño a ser escuchado, se establece la necesidad de que el niño, que es sujeto de derechos pero sin plena autonomía, sea escuchado en la interpretación y aplicación de los derechos que contiene la Convención. En la configuración y definición de este derecho, bajo el principio de igualdad y no discriminación, debe tenerse en cuenta a los niños que tienen mayores dificultades para hacer oír su opinión, entre ellos los niños con discapacidad, quienes deben poder contar con los modos de comunicación que necesiten para facilitar la expresión de sus opiniones. Asimismo, celebra la adopción de la CRPD, cuyo art. $7^{12}$ establece que deberán recibir los apoyos apropiados a su discapacidad y edad para ejercer este derecho. El derecho a ser escuchado opera en el derecho a la salud, y para que los niños con discapacidad puedan participar en el proceso de toma de decisiones, la información que se les dé debe ser apropiada y accesible. Nótese que se habla de 'apropiado' o ‘adecuado' y no de 'especial'. En lo relativo a las actividades lúdicas, recreativas, deportivas y culturales, establece que los niños deben participar en ellas, y en lo que se refiere a los niños muy pequeños y algunos con discapacidad que no puedan participar en los procesos oficiales, señala que se les debe brindar oportunidades 'especiales' de expresar sus preferencias. De nuevo, llama la atención que, aplicando el modelo médico, el acento se ponga en el niño y no en el proceso general, que es el que debe ser inclusivo y prever mecanismos de equiparación de oportunidades conforme al modelo de derechos humanos.

Dentro de los mecanismos de garantía de ejercicio de este derecho, menciona la accesibilidad, la atención a la diversidad, el hecho de que deben estar adaptados a la capacidad evolutiva de los niños, y el carácter inclusivo y no discriminatorio. Ninguno de estos principios prevé de forma expresa la discapacidad; por ello, si bien podría interpretarse que queda cubierta y de forma positiva por la accesibilidad, la diversidad,

I2. El artículo 7 de la CDPD se refiere a los niños y niñas con discapacidad. el apoyo según necesidades, también plantea dudas, precisamente por no afianzarse sobre una definición del principio de igualdad y no discriminación por motivo de discapacidad, y porque, como se ha mostrado en algunos puntos, ha sido ambivalente entre ambos modelos.

La Observación General $n^{\circ}$ I 3 : derecho del niño a no ser objeto de ninguna forma de violencia alerta de la magnitud e intensidad de la violencia ejercida contra los niños; de hecho recomienda la difusión de la propia Observación y establece que deberá ser traducida a los idiomas propios, incluida la lengua de signos, el braille y en formatos fáciles de leer para los niños con discapacidad ${ }^{\mathrm{i}}$. El comité denuncia que la violencia es una causa de discapacidad y dedica parte de su articulado a establecer la obligatoriedad de adoptar las medidas apropiadas y de prevención de cualquier forma de violencia, incluida la que está basada en género, la raza, el color, la religión, el origen étnico o social, o la discapacidad, de forma que todos queden igualmente protegidos. Denuncia que los niños con discapacidad están más expuestos a sufrir violencia, entre otros motivos, por el abandono o las esterilizaciones forzadas de las niñas con discapacidad. Para prevenir la violencia, invita a que los Estados a identificar las causas y factores de riesgo; a ejercer mayor control sobre los grupos de niños con más riesgo, como los niños con discapacidad, a los que, además, se les deberá proveer de los ajustes razonables que sean precisos, para que tengan las mismas posibilidades de comunicarse e identificar este tipo de situaciones o de participar en procesos judiciales; y, por último, a combatir las actitudes que perpetúan la violencia basadas, entre otras causas, en la discapacidad. En definitiva, les marca transversalizar a los colectivos vulnerables en los marcos nacionales de coordinación, que deben incorporarlos en todas las medidas (legislativas, administrativas, sociales y educativas) y en todas las etapas de la intervención (desde la prevención hasta la recuperación y la reintegración); además, en las medidas sociales que se apliquen se deben poder identificar lo que denomina realidades ocultas, entre las que se encuentran las vividas por

I3. Hace una remisión genérica a la discapacidad, sin identificar el tipo. 
los niños con discapacidad. Y como medida clave, les invita a la ratificación de la CDPD.

Actualmente existen tres avances de OO.GG. sin editar: la $n^{\mathrm{O}} \mathrm{I} 5$, la $\mathrm{n}^{\mathrm{O}} \mathrm{I} 6$ y la ${ }^{\mathrm{o}} \mathrm{I} 7^{\mathrm{I}}$.

La Observación General no I 5 : el derecho del niño a disfrutar del más alto estado de salud relaciona discriminación y vulnerabilidad, y proscribe cualquier discriminación, entre otros, por motivos de discapacidad. Dentro del ámbito de la salud, muestra profunda preocupación por las discapacidades psicosociales, tanto en lo relativo a su incidencia, a su correcto tratamiento, como a prevenir el exceso de medicalización y a que sean cuidados en la comunidad, por lo que la institucionalización u hospitalización debe acordarse sustentada en el principio del mayor interés del menor. Reconoce la existencia de barreras (económicas, institucionales y culturales) en el acceso a la salud, por lo que establece que deben ser eliminadas y si bien no identifica las físicas, posteriormente incorpora la accesibilidad, estableciendo que la información sobre la salud debe ser físicamente accesible, entendible y apropiada para todos los niños y que los Estados Partes, en sus planes de acción, deben incluir: a) la no discriminación; b) la accesibilidad física, que en el caso de niños y mujeres con discapacidad puede requerir atención adicional a sus necesidades; c) y la asequibilidad económica; d) la accesibilidad de la información, la cual debe darse en formatos accesibles y entendibles para los niños y sus cuidadores. Pero sigue sin reconocer la relación entre barrera y discriminación, entre barrera y discapacitación. En la dualidad discapacidad como cuestión que se ha de proteger y como cuestión que se ha de prevenir, reconoce que existen situaciones, como la discapacidad, que pueden ser prevenidas conociendo sus causas y mediante la asignación de recursos, e insta a que la recopilación de información se desagregue, entre otros criterios, por discapacidad.

La Observación General $n^{\circ}$ I6: las obligaciones de los Estados en relación a los impactos de las

I4. En la página oficial del Comité de Derechos del Niño de Naciones Unidas, de la OO.GG. ${ }^{\circ}$ I 3 se pasa a la I 5 . empresas en los derechos de los niños mantiene la misma línea que las anteriores OO.GG. del CRC: afirma el principio de igualdad y no discriminación, visibilizando a los niños con discapacidad, a quienes identifica como vulnerables en diferentes ocasiones, pero sigue sin definir la discriminación y, por tanto, sin incluir mecanismos garantistas de equiparación. Además, aunque invoca la CDPD, no menciona el diseño para todos o la accesibilidad de los bienes, servicios y entornos y, por tanto, se pierde una gran oportunidad para visibilizar el impacto en violaciones de derechos de los niños con discapacidad derivado de que esos bienes, servicios o entornos no estén diseñados teniéndolos en cuenta y no puedan ejercitar su derecho. Sin embargo, recupera la memoria de la accesibilidad en el ámbito procesal, y así, señala que el derecho de los niños a ser oídos por las empresas cuando sus actividades les afecten debe ser mediante procesos accesibles e inclusivos. También establece similares garantías en el caso de interposición de recursos contra las empresas cuando haya violaciones de derechos.

El derecho al ocio, al juego y al disfrute está incluido en la Observación General $n^{\circ}$ I7, que lo describe como un punto esencial de su desarrollo e inclusión en la comunidad. Especialmente menciona que este derecho debe realizarse en igualdad de condiciones para todos los niños, y recuerda que algunos encuentran dificultades, como cuando existe una discapacidad. Explicita las numerosas barreras físicas y mentales, y los estereotipos que impiden el acceso a este derecho, por lo que aplaude las previsiones que, sobre este derecho, hace la CDPD. De hecho, en la relectura que hace del art. 23 de la Convención de los Derechos del $N i \tilde{n} O^{15}$ recuerda que los entornos deben ser accesibles e inclusivos. Por otra parte, alerta de que el derecho al ocio puede verse vulnerado cuando los niños están sujetos a programas y horarios de actividades estrictos, como en el caso de sesiones de rehabilitación para los niños con discapacidad. Entre las acciones que marca a los Estados, se destaca que deben

I 5. Es el artículo dedicado de forma exclusiva a los niños y niñas con discapacidad. 
incluir información desagregada sobre el disfrute de este derecho, entre otras variables, por discapacidad; revisar los presupuestos para que incluyan cuestiones relativas a accesibilidad; invertir en diseño universal; y reforzar la accesibilidad de las escuelas. Y en cuanto a la difusión de esta Observación, conmina a que se incluya su edición en braille o en formato de fácil lectura para niños con discapacidad ${ }^{\mathrm{I}}$.

Conforme se ha visto, el CRC, si bien incluye una Observación específica relativa a discapacidad y trata de forma extensiva la realidad de los niños con discapacidad, su gran dificultad es la falta de una definición de discriminación por motivo de discapacidad que establezca una línea clara en la equiparación de derechos de los niños y niñas con discapacidad y que señale al Estado y a la sociedad como garantes, mediante la prevención y la eliminación de barreras. Esta falta de definición y de interiorización de la igualdad en derechos se refleja en un tratamiento asistemático y desigual en la definición de algunos de sus derechos, y en las consecuencias que atribuye en caso de conculcaciones de derechos a los niños y niñas con discapacidad en relación a otros. Si bien la aprobación de la CDPD le da un impulso, al menos terminológico y en cierta medida conceptual, no es suficiente, pues no está plenamente interiorizado el cambio de paradigma que supone el modelo de derechos humanos.

9. Observaciones Generales del Comité para la Protección de los Derechos de Todos los Trabajadores Migratorios y de sus Familiares

Este comité, que es el encargado de velar por la Convención internacional sobre la Protección de los Derechos de Todos los Trabajadores Migratorios y de sus Familiares, de I990, sólo ha elaborado una Observación: la Observación General $n^{o}$ I: sobre los trabajadores domésticos migratorios, en la que la discapacidad, pese a que

I6. No identifica tipo de discapacidad. la CDPD ya ha sido aprobada, no aparece. Esta invisibilización puede deberse, entre otras, a dos causas: por un lado, a la idea de la discapacidad como incapacidad para trabajar; y por otro, a la reticencia que puedan tener los Estados de empleo a admitir la migración de personas con discapacidad por considerarlas una mayor carga, lo que es un atentado a su dignidad e igualdad.

10. Observaciones Generales del Comité para la Protección de Todas las Personas contra las Desapariciones Forzadas

Este comité, encargado de velar por la Convención Internacional para la Protección de Todas las Personas contra las Desapariciones Forzadas, de 2006, aún no ha elaborado ninguna Observación.

\section{Conclusiones}

La inclusión de la discapacidad por parte de los diferentes comités de derechos humanos es, como se ha visto, desde invisible a titubeante. No existe una inclusión expresa y sistemática desde el modelo de derechos humanos.

De todos los comités, sólo tres han elaborado una Observación General específica, el CESCR, el CRC y el CEDAW, pero con una orientación y contenido diferentes. De ellos, el CESCR es el único que ha definido el concepto de discriminación por razón de discapacidad, lo que le ha dado una mayor orientación al modelo de derechos humanos. El CRC lo ha tratado de forma intensa, pero sin ser capaz de incluir una definición de discriminación por motivo de discapacidad, por lo que su interiorización del modelo de derechos humanos es aún más titubeante. Ello hace que sus OO.GG., aunque se muevan entre ambos modelos, sigan siendo deudoras del modelo médico, pues no dan 
una pauta que identifique que las barreras son violaciones de derechos y asumen, en ocasiones, como natural la exclusión. Y por último, el CEDAW, si bien la incluye, es de una forma muy menor y con poco contenido. El resto de comités, o bien la invisibilizan, o bien las incluyen transversalmente, pero tampoco asumen el modelo de derechos humanos, siendo su relación incluso más ambivalente.

Ni siquiera la aprobación de la CDPD ha logrado un 'efecto llamada' sobre los diferentes comités, y si bien en algunos se producen remisiones parciales, o se adoptan algunos conceptos, en el fondo no se ha interiorizado el cambio de paradigma que conlleva pasar del modelo médico (que asume la desigualdad como natural) al modelo de derechos humanos (que reivindica la equiparación de oportunidades). Tampoco en una visión comparada las OO.GG. de los comités guardan una coherencia entre ellas en la forma de tratarla. En definitiva, no existe una plena traslación del lenguaje de derechos humanos y discapacidad que la CDPD supone.

Pero, sin duda, la CDPD es el texto básico que deben asumir los comités de derechos humanos. Desde las consideraciones que hace, es necesario:

- Visibilizar la discapacidad desde su propia diversidad y desde el modelo de derechos humanos.

- Asumir, del modelo de derechos humanos, que proclama la equiparación de oportunidades, la igual dignidad y valor de las personas con discapacidad. Ésta es una cuestión clave para erradicar estereotipos e imágenes negativas.

- Incluir la definición de discriminación, las causas que la originan y los mecanismos que garantizan la igualdad. Sin definición, no es posible hablar de modelo de derechos humanos, porque no se reconoce la igualdad de derechos desde la equiparación; de hecho se ha visto cómo se arrastra el modelo médico y se asume que la discapacidad es causa natural de exclusión o se tratan derechos que quedan en el aire, como el derecho a vivir en comunidad frente a la institucionalización.
- Incorporar los mecanismos de equiparación que prevé la CDPD y que permiten erradicar desigualdades estructurales fundamentadas tanto en barreras físicas (en sentido amplio) como mentales (no identificación de la discapacidad como una cuestión de derechos humanos). Significa e implica asumir y defender el concepto de dignidad desde la equiparación de oportunidades y la igualdad de valor de todo ser humano.

- $\quad$ Clarificar, unificar y remitirse a la terminología usada por la CDPD, de forma que se logre un marco común, entendible y compartido por todos. Así, de 'especial' se pasaría a 'específico', o cuando se hablara de las diferentes dimensiones de la accesibilidad en lo relativo a las personas con discapacidad, se asumiría lo estipulado en la CDPD, igual que cuando se hablara de ajustes razonables o de comunicación y formatos accesibles, en su doble dimensión física y de contenidos. En definitiva, implica facilitar la lectura de las OO.GG., pues se unifican y clarifican los conceptos

El reconocimiento de la discapacidad como una cuestión de derechos humanos a través de la CDPD crea un marco nuevo y dinámico desde el que leer y aplicar los tratados internacionales de derechos humanos en relación a este colectivo, que debe facilitar la superación del modelo médico por parte de los demás comités. La CDPD es, por tanto, un marco común y universal que debe ser incluido como referente y clarificador para todos los comités en su tratamiento de la discapacidad. Esta asunción, además, tendrá efecto directo en todos los Estados Partes de los diferentes tratados, pues recordemos que las personas con discapacidad están protegidas e incluidas en todos los tratados internacionales de derechos humanos, y que lo que la CDPD aporta son las claves del lenguaje de derechos humanos. La CDPD, a través de su propio comité, de las organizaciones de personas con discapacidad, de las organizaciones de derechos humanos, debe expandirse, por lo que éstas deben incidir y reclamar el respeto y remisión a la Convención por parte del resto de comités. 


\section{Referencias bibliográficas}

Degener, T. (I999): "International disability law - A new legal subject on the rise: The interregional expert's meeting in Hong Kong, December 13-17, I999", Berkeley Journal of International Law, I 8, I80-I95.

Jones, M. y Basser M. (I999): "Law and the social construction of disability", en Jones, M. y Basser Marks L.A. (eds.), Dis-ability, Diversability and Legal Change, Den Haag: Martinus Nijhoff Publisersh, 3-24.

Quin, G. y Degener, T. (2002): Derechos humanos $y$ discapacidad. Uso actual y posibilidades futuras de los instrumentos de derechos bumanos de las Naciones Unidas en el contexto de la discapacidad, Ginebra: Naciones Unidas.
Trömel, S. (2010): Social model of disability and CRPD as a human rights treaty and a tool for social development [mensaje electrónico], IDA CRPD Forum, 28 de mayo.

VV.AA. (2007): De la exclusión a la igualdad. Hacia el pleno ejercicio de los derechos de las personas con discapacidad. Manual para parlamentarios sobre la Convención sobre los Derechos de las Personas con Discapacidad y su Protocolo Facultativo, Naciones Unidas. Ginebra: Oficina del Alto Comisionado de las Naciones Unidas para los Derechos Humanos; Unión Interparlamentaria. 
Anexo: Observaciones Generales de los comités de derechos humanos de la ONU ${ }^{17}$

\section{COMITÉ DE DERECHOS HUMANOS}

\section{Human Rights Committee}

$<$ http://www2.ohchr.org/english/bodies/hrc/

comments.htm>

Observación General $n^{\circ}$ 34: artículo I9, libertad de opinión y libertad de expresión, $102^{\circ}$ periodo de sesiones, CCPR/C/GC/34, 20 II.

General Comment No. 33: The Obligations of States Parties under the Optional Protocol to the International Covenant on Civil and Political Rights, $94^{\circ}$ periodo de sesiones, CCPR/C/GC/33, 2008.

General Comment No. 32: Article I4, Right to Equality before Courts and Tribunals and to a Fair Trial, $90^{\circ}$ periodo de sesiones, CCPR/C/ GC/32, 2007.

General Comment No. 3 I: The Nature of the General Legal Obligation Imposed on States Parties to the Covenant, $80^{\circ}$ periodo de sesiones, CCPR/C/2I/Rev. I/Add. I3, 2004.

General Comment No. 30: Reporting Obligations of States Parties under Article 40 of the Covenant, $2.025^{\text {a }}$ sesión, CCPR/C/2I/Rev.2/ Add.I 2, 2002.

General Comment No. 29: States of Emergency (Article 4), I.950 a sesión, CCPR/C/2I/Rev.I/ Add.r I, 200I.

General Comment No. 28: Equality of Rights between Men and Women (Article 3), $68^{\circ}$ periodo de sesiones, CCPR/C/2 I/Rev.I/Add.ıo, 2000 .

General Comment No. 27: Freedom of Movement (Art. I2), $67^{\circ}$ periodo de sesiones, CCPR/C/2 I/ Rev.r/Add.9, I999.

General Comment No. 26: Continuity of Obligations, $6 \mathrm{I}^{\circ}$ periodo de sesiones, $\mathrm{I} 997$.

Comment No. 25: The Right to Participate in Public Affairs, Voting Rights and the Right of
Equal Access to Public Service (Art. 25), $57^{\circ}$ periodo de sesiones, CCPR/C/GC/25, 1996.

General Comment No. 24: Issues Relating to Reservations Made upon Ratification or Accession to the Covenant or the Optional Protocols thereto, or in Relation to Declarations under Article 4I of the Covenant, $52^{\circ}$ periodo de sesiones, I994.

General Comment No. 23: The Rights of Minorities (Art. 27), 50 periodo de sesiones, I 994.

General Comment No. 22: The Right to Freedom of Thought, Conscience and Religion (Art. I8), $48^{\circ}$ periodo de sesiones, 1993 .

General Comment No. 21: Replaces General Comment 9 Concerning Humane Treatment of Persons Deprived of Liberty (Art. Io), $44^{\circ}$ periodo de sesiones, I992.

General Comment No. 20: Replaces General Comment 7 Concerning Prohibition of Torture and Cruel Treatment or Punishment (Art. 7), $44^{\circ}$ periodo de sesiones, 1992.

General Comment No. I9: Protection of the Family, the Right to Marriage and Equality of the Spouses (Art. 23), $39^{\circ}$ periodo de sesiones, I990.

General Comment No. I8: Non-discrimination, $37^{\circ}$ periodo de sesiones, I989.

General Comment No. I7: Rights of the Child (Art. 24), $3 \mathrm{I}^{\mathrm{O}}$ periodo de sesiones, I989.

General Comment No. I6: The Right to Respect of Privacy, Family, Home and Correspondence, and Protection of Honour and Reputation (Art. I7), $32^{\circ}$ periodo de sesiones, I988.

General Comment No. I5: The Position of Aliens under the Covenant, $27^{\circ}$ periodo de sesiones, I986.

General Comment No. I4: Nuclear Weapons and the Right to Life (Art. 6), $23^{\circ}$ periodo de sesiones, I984.

I7. Se citan en el orden que aparecen en la web de Naciones Unidas. No se incluye el Comité de los Derechos de las Personas con Discapacidad. 
General Comment No. 13: Equality before the Courts and the Right to a Fair and Public Hearing by an Independent Court Established by Law (Art. I4), $2 \mathrm{I}^{\circ}$ periodo de sesiones, I984.

General Comment No. I2: The Right to Selfdetermination of Peoples (Art. I), 2 $\mathrm{I}^{\mathrm{o}}$ periodo de sesiones, 1984 .

General Comment No. I I: Prohibition of Propaganda for War and Inciting National, Racial or Religious Hatred (Art. 20), $19^{\circ}$ periodo de sesiones, I983.

General Comment No. Io: Freedom of Expression (Art. I9), $9^{\circ}$ periodo de sesiones, I983.

General Comment No. 09: Humane Treatment of Persons Deprived of Liberty (Art. Io), I $6^{\circ}$ periodo de sesiones, I982.

General Comment No. 08: Right to Liberty and Security of Persons (Art. 9), $16^{\circ}$ periodo de sesiones, 1982 .

General Comment No. 07: Torture or Cruel, Inbuman or Degrading Treatment or Punishment (Art. 7), I $6^{\circ}$ periodo de sesiones, I982.

General Comment No. 06: The Right to Life (Art. 6), $16^{\circ}$ periodo de sesiones, I982.

General Comment No. 05: Derogation of Rights (Art. 4), I3 ${ }^{\circ}$ periodo de sesiones, I98I.

General Comment No. 04: Equality between the Sexes (Art. 3), I $3^{\circ}$ periodo de sesiones, I98 I.

General Comment No. 03: Implementation at the National Level (Art. 2), $13^{\circ}$ periodo de sesiones, I98I.

General Comment No. 02: Reporting Guidelines, $\mathrm{I} 3^{\circ}$ periodo de sesiones, I98 I (nota: ha sido sustituda por el documento CCPR/C/66/GUI, Consolidated Guidelines for State Reports under the International Covenant on Civil and Political Rights, de 29 de septiembre de 1999).

General Comment No. I: Reporting Obligation, I $3{ }^{\circ}$ periodo de sesiones, I98 I.

\section{COMITÉ DE DERECHOS ECONÓMICOS, SOCIALES Y CULTURALES}

Committee on Economic, Social and Cultural Rights

<http://www2.ohchr.org/english/bodies/cescr/ comments.htm>

General Comment No. 2I: Right of Everyone to Take Part in Cultural Life, $43^{\circ}$ periodo de sesiones, E/C.I 2/GC/2 I/Rev. I, 20 Iо.

General Comment No. 20: Non-Discrimination in Economic, Social and Cultural Rights (Art. 2, Para. 2), $42^{\circ}$ periodo de sesiones, E/C.I $2 /$ $\mathrm{GC} / 20,2009$.

General Comment No. I9: The Right to Social Security (Art. 9), $39^{\circ}$ periodo de sesiones, E/C.I2/GC/I9, 2008.

General Comment No. I8: The Right to Work, $35^{\circ}$ periodo de sesiones, E/C.I2/GC/I8, 2006.

General Comment No. 17: The Right of Everyone to Benefit from the Protection of the Moral and Material Interests Resulting from any Scientific, Literary or Artistic Production of which He or She is the Author (Article I5, Paragraph I (c), of the Covenant), $35^{\circ}$ periodo de sesiones, E/C.I 2/GC/I7, 2006.

General Comment No. I6: The Equal Right of Men and Women to the Enjoyment of All Economic, Social and Cultural Rights, $34^{\circ}$ periodo de sesiones, E/C.I 2/2005/3, 2005.

General Comment No. 15: The Right to Water, $29^{\circ}$ periodo de sesiones, E/C.I2/2002/II, 2002.

General Comment No. I4: The Right to the Highest Attainable Standard of Health, $22^{\circ}$ periodo de sesiones, E/C.I $2 / 2000 / 4,2000$.

General Comment No. I3: The Right to Education, 2 I $^{\circ}$ periodo de sesiones, E/C.I 2/I999/IO, I999.

General Comment No. I2: Right to Adequate Food, $20^{\circ}$ periodo de sesiones, E/C.I 2/I999/5, I999.

General Comment No. I I: Plans of Action for Primary Education (Article I 4 of the International Covenant on Economic, Social and Cultural Rights), $20^{\circ}$ periodo de sesiones, E/C.I2/I999/4, I999. 
Draft General Comment No. Io: The Role of National Human Rights Institutions in the Protection of Economic, Social and Cultural Rights, $19^{\circ}$ periodo de sesiones, E/C.I2/I998/25, I998.

Draft General Comment No. 9: The Domestic Application of the Covenant, $19^{\circ}$ periodo de sesiones, E/C.I2/I998/24, I998.

General Comment No. 8: The Relationship between Economic Sanctions and Respect for Economic, Social and Cultural Rights, $\mathrm{I} 7^{\circ}$ periodo de sesiones, E/C.I2/I997/8, I997.

General Comment No. 7: The Right to Adequate Housing (Art. II.I of the Covenant): Forced Evictions, $16^{\circ}$ periodo de sesiones, 1997.

General Comment No. 6: The Economic, Social and Cultural Rights of Older Persons, $\mathrm{I}^{\circ}$ periodo de sesiones, E/I996/22 at 20, I996.

General Comment No. 5: Persons with Disabilities, I I $^{\circ}$ periodo de sesiones, E/I995/22 at I9, I995.

General Comment No. 4: The Right to Adequate Housing (Art.I I (I) of the Covenant), $6^{\circ}$ periodo de sesiones, I99I.

General Comment No. 3: The Nature of States Parties Obligations (Art. 2, Para. I of the Covenant), $5^{\circ}$ periodo de sesiones, I990.

General Comment No. 2: International Technical Assistance Measures (Art. 22 of the Covenant), $4^{\circ}$ periodo de sesiones, I990.

General Comment No. I: Reporting by States Parties, $3^{\text {er }}$ periodo de sesiones, I989.

\section{COMITÉ PARA LA ELIMINACIÓN \\ DE LA DISCRIMINACIÓN RACIAL}

\section{Committee on the Elimination of Racial} Discrimination

<http://www2.ohchr.org/english/bodies/cerd/ comments.htm>

General Recommendation No. 34: Racial Discrimination against People of African Descent, $79^{\circ}$ periodo de sesiones, CERD/C/ $\mathrm{GC} / 34,20 \mathrm{II}$.
General Recommendation No. 33: Follow-up to the Durban Review Conference, $65^{\circ}$ periodo de sesiones, CERD/C/GC/33, 2009.

General Recommendation No. 32: The Meaning and Scope of Special Measures in the International Convention on the Elimination of All Forms Racial Discrimination, $75^{\circ}$ periodo de sesiones, CERD/C/GC/32, 2009.

General Recommendation No. 3 I: On the Prevention of Racial Discrimination in the Administration and Functioning of the Criminal Justice System, en A/60/I 8, 2005.

General Recommendation No. 30: Discrimination against Non Citizens, 2004.

General Recommendation No. 29: Article I, Paragraph I of the Convention (Descent), 6I ${ }^{\circ}$ periodo de sesiones, 2002.

General Recommendation No. 28: The Followup to the World Conference against Racism, Racial Discrimination, Xenophobia and Related Intolerance, $60^{\circ}$ periodo de sesiones, en $\mathrm{A} / 57 / \mathrm{I} 8,2002$.

General Recommendation No. 27: Discrimination against Roma, $57^{\circ}$ periodo de sesiones, en $\mathrm{A} / 55 / \mathrm{I} 8$, anexo V at I 54, 2000.

General Recommendation No. 26: Article 6 of the Convention, $56^{\circ}$ periodo de sesiones, en $\mathrm{A} / 5$ 5/1 8, anexo V., 2000.

General Recommendation No. 25: Gender Related Dimensions of Racial Discrimination, $56^{\circ}$ periodo de sesiones, en $\mathrm{A} / 55^{2} / \mathrm{I} 8$, anexo $\mathrm{V}$ at I $52,2000$.

General Recommendation No. 24: Reporting of Persons Belonging to Different Races, Nationall Ethnic Groups, or Indigenous Peoples (Art. I), $55^{\circ}$ periodo de sesiones, en $\mathrm{A} / 54 / \mathrm{I} 8$, anexo V, I999.

General Recommendation No. 23: Rights of Indigenous Peoples, $5 \mathrm{I}^{\circ}$ periodo de sesiones, en $\mathrm{A} / 52 / \mathrm{I} 8$, anexo $\mathrm{V}$ at I22, 1997.

General Recommendation No. 22: Refugees and Displaced Persons, $49^{\circ}$ periodo de sesiones, en $\mathrm{A} / 5$ I/I 8, anexo VIII at I26, I996.

General Recommendation No. 2I: Right to Selfdetermination, $48^{\circ}$ periodo de sesiones, en A/5I/I 8, I996. 
General Recommendation No. 20: Nondiscriminatory Implementation of Rights and Freedoms (Art. 5), $48^{\circ}$ periodo de sesiones, en A/5I/I 8, 1996.

General Recommendation No. I9: Racial Segregation and Apartheid (Art. 3), $47^{\circ}$ periodo de sesiones, en $\mathrm{A} / 5$ O/I 8, I995.

General Recommendation No. I8: Establishment of an International Tribunal to Prosecute Crimes against Humanity, $44^{\circ}$ periodo de sesiones, en $\mathrm{A} / 49$ /г 8, I994.

General Recommendation No. 17: Establishment of National Institutions to Facilitate Implementation of the Convention, $42^{\circ}$ periodo de sesiones, en $\mathrm{A} / 48 / 18$, I993.

General Recommendation No. I6: References to Situations Existing in Other States (Art. 9), $42^{\circ}$ periodo de sesiones, en A/48/18, I993.

General Recommendation No. 15: Organized Violence Based on Ethnic Origin (Art. 4), $42^{\circ}$ periodo de sesiones, en $\mathrm{A} / 48$ / 8 , I993.

General Recommendation No. I4: Definition of Discrimination (Art. I, Par. I), $42^{\circ}$ periodo de sesiones, en $\mathrm{A} / 48 /$ I 8 , I993.

General Recommendation No. I3: Training of Law Enforcement Officials in the Protection of Human Rights, $42^{\circ}$ periodo de sesiones, en $\mathrm{A} / 48 /$ I 8 , I993.

General Recommendation No. I2: Successor States, $42^{\circ}$ periodo de sesiones, en $\mathrm{A} / 48 / \mathrm{I} 8, \mathrm{I} 993$.

General Recommendation No. I I: Non-citizens (Art. I), $42^{\circ}$ periodo de sesiones, en $\mathrm{A} / 46 / \mathrm{I} 8$, 1993.

General Recommendation No. Io: Technical Assistance, $39^{\circ}$ periodo de sesiones, en $\mathrm{A} / 46 / \mathrm{I} 8$, I99I.

General Recommendation No. 09: Independence of Experts (Art. 8, Par.I), $38^{\circ}$ periodo de sesiones, en $\mathrm{A} / 45 / 18$, I990.

General Recommendation No. o8: Identification with a Particular Racial or Ethnic Group (Art.I, Par.I \& 4), $38^{\circ}$ periodo de sesiones, en $\mathrm{A} / 45 / 18$, I990.

General Recommendation No. 07: Legislation to Eradicate Racial Discrimination (Art. 4), $32^{\circ}$ periodo de sesiones, en A/40/I8, I985.
General Recommendation No. o6: Overdue Reports (Art. 9), $2 \mathrm{I}^{\circ}$ periodo de sesiones, en $\mathrm{A} / 37 / \mathrm{I} 8$, I982.

General Recommendation No. 05: Reporting by States Parties (Art. 7), $15^{\circ}$ periodo de sesiones, en $\mathrm{A} / 32 / 18$, I977.

General Recommendation No. 04: Demographic Composition of the Population (Art. 9), $8^{\circ}$ periodo de sesiones, en A/9018, I973.

General Recommendation No. 03: Apartheid (Art. 3), $6^{\circ}$ periodo de sesiones, en A/8718, I972.

General Recommendation No. 02: States Parties Obligations (Art. 9), $5^{\circ}$ periodo de sesiones, en $\mathrm{A} / 87$ I 8 , I972.

General Recommendation No. o : States Parties' Obligations (Art. 4), $5^{\circ}$ periodo de sesiones, 1972.

\section{COMITÉ PARA LA ELIMINACIÓN DE LA DISCRIMINACIÓN CONTRA LA MUJER} Committee on the Elimination of all Forms of Discrimination against Women

$<$ <ttp://www2.ohchr.org/english/bodies/cedaw/ comments.htm>

General Recommendation, No. 29: Article I6 Economic Consequences of Marriage, Family Relations and Their Dissolution, $54^{\circ}$ periodo de sesiones, EDAW/C/GC/29, 2013.

General Recommendation No. 28: The Core Obligations of States Parties under Article 2 of the Convention on the Elimination of All Forms of Discrimination against Women, $47^{\circ}$ periodo de sesiones, CEDAW/C/GC/28, 2010 .

General Recommendation No. 27: Older Women and Protection of Their Human Rights, $47^{\circ}$ periodo de sesiones, CEDAW/C/GC/27, 2010.

General Recommendation No. 26: Women Migrant Workers, $42^{\circ}$ periodo de sesiones, 2008.

General Recommendation No. 25: On Article 4, Paragraph I, of the Convention on the Elimination of All Forms of Discrimination against Women, on Temporary Special Measures, $30^{\circ}$ periodo de sesiones, 2004. 
General Recommendation General Recommendation No. 24: Women and Health, $20^{\circ}$ periodo de sesiones, $\mathrm{A} / 54 / 38$ at 5 , I999.

General Recommendation No. 23: Women in Political and Public Life, $16^{\circ}$ periodo de sesiones, I997.

General Recommendation No. 22: Article 20 of the Convention, $14^{\circ}$ periodo de sesiones, I995.

General Recommendation No. 2I: Equality in Marriage and Family Relations, $13^{\circ}$ periodo de sesiones, I994.

General Recommendation No. 20: Reservations, II $^{\circ}$ periodo de sesiones, I 992.

General Recommendation I9: Violence against Women, I I $^{\circ}$ periodo de sesiones, en $\mathrm{A} / 47 / 38$ at I, I993.

General Recommendation No. I8: Disabled Women, I0 ${ }^{\circ}$ periodo de sesiones, $\mathrm{A} / 46 / 38$ at 3 , I 993 .

General Recommendation No. I7: Measurement and Quantification of the Unremunerated Domestic Activities of Women and Their Recognition in the GNP, $10^{\circ}$ periodo de sesiones, I99I.

General Recommendation No. I6: Unpaid Women Workers in Rural and Urban Family Enterprises, $10^{\circ}$ periodo de sesiones, I99I.

General Recommendation No. I5: Women and AIDS, $9^{\circ}$ periodo de sesiones, I990.

General Recommendation No. I4: Female Circumcision, $9^{\circ}$ periodo de sesiones, I990.

General Recommendation No. I3: Equal Remuneration for Work of Equal Value, $8^{\circ}$ periodo de sesiones, I989.

General Recommendation No. I2: Violence against Women, $8^{\circ}$ periodo de sesiones, en $\mathrm{A} / 44 / 38$ at 75 , 1990.

General Recommendation No. II: Technical Advisory Services for Reporting, $8^{\circ}$ periodo de sesiones, I989.

General Recommendation No. IO: Tenth Anniversary of the Adoption of CEDAW, $8^{\circ}$ periodo de sesiones, I989.

General Recommendation No. 9: Statistical Data, $8^{\circ}$ periodo de sesiones, I989.
General Recommendation No. 8: Article 8, $7^{\circ}$ periodo de sesiones, I988.

General Recommendation No. 7: Resources, $7^{\circ}$ periodo de sesiones, I988.

General Recommendation No. 6: Effective National Machinery and Publicity, $7^{\circ}$ periodo de sesiones, 1988 .

General Recommendation No. 5: Temporary Special Measures, $7^{\circ}$ periodo de sesiones, I988.

General Recommendation No. 4: Reservations, $6^{\circ}$ periodo de sesiones, 1987 .

General Recommendation No. 3: Education and Public Information Programmes, $6^{\circ}$ periodo de sesiones, 1987.

General Recommendation No. 2: Reporting Guidelines, $6^{\circ}$ periodo de sesiones, 1987.

General Recommendation No. I: Reporting Guidelines, $5^{\circ}$ periodo de sesiones, 1986

\section{COMITÉ CONTRA LA TORTURA}

\section{Committee against Torture}

$<$ http://www2.ohchr.org/english/bodies/cat/ comments.htm>

General Comment No. 3: Implementation of Article I4 (Redress for Victims of Torture) by States Parties, CAT/C/GC/3, $20 \mathrm{I} 2$.

General Comment No. 2: Implementation of Article 2 by States Parties, $39^{\circ}$ periodo de sesiones, CAT/C/GC/2, 2008.

General Comment No. I: Implementation of Article 3 of the Convention in the Context of Article 22 (Refoulement and Communications), $\mathrm{I} 6^{\circ}$ periodo de sesiones, en A/53/44, anexo IX, I997.

\section{COMITÉ PARA LOS DERECHOS DEL NIÑO}

\section{Committee on the Rights of the Child}

<http://www2.ohchr.org/english/bodies/crc/ comments.htm>

General Comment No. 17: The Right of the Child to Rest, Leisure, Play, Recreational Activities, 
Cultural Life and the Arts - Advance Unedited Version, CRC/C/GC/I, 20I3.

General Comment No. I6, On State Obligations Regarding the Impact of the Business Sector on Children's Rights, CRC/C/GC/I6, 2013.

General Comment No. 15: The Right of the Child to the Enjoyment of the Highest Attainable Standard of Health (Article. 24) - Advance Unedited Version, CRC/C/GC/I 5, 20I3.

General Comment No. I3: The Right of the Child to Freedom from All Forms of Violence, CRC/C/GC/I3, 201 I.

General Comment No. I2: The Right of the Child to Be Heard, $55^{\circ}$ periodo de sesiones, CRC/C/ GC/I 2, 2009 .

General Comment No. I I: Indigenous Children and Their Rights under the Convention, $50^{\circ}$ periodo de sesioness, CRC/C/GC/I I, 2009.

General Comment No. Io: Children's Rights in Juvenile Justice, $44^{\circ}$ periodo de sesiones, CRC/C/GC/Io, 2007.

General Comment No. 9: The Rights of Children with Disabilities, $43^{\circ}$ periodo de sesiones, $\mathrm{CRC} / \mathrm{C} / \mathrm{GC} / 9,2007$.

General Comment No. 8: The Right of the Child to Protection from Corporal Punishment and Other Cruel or Degrading Forms of Punishment (Arts. 19; 28, Para. 2; and 37, Inter Alia), $42^{\circ}$ periodo de sesiones, CRC/C/GC/8, 2006.

General Comment No. 7: Implementing Child Rights in Early Childhood, $40^{\circ}$ periodo de sesiones, CRC/C/GC/7/Rev. I, 2006.

General Comment No. 6: Treatment of Unaccompanied and Separated Children Outside their Country of Origin, $39^{\circ}$ periodo de sesiones, CRC/GC/2005/6, 2005 .

General Comment No. 5: General Measures of Implementation of the Convention on the Rights of the Child, $34^{\circ}$ periodo de sesiones, $\mathrm{CRC} / \mathrm{GC} / 2003 / 5,2003$.

General Comment No. 4: Adolescent Health and Development in the Context of the Convention on the Rights of the Child, $33^{\circ}$ periodo de sesiones, 2003 .
General Comment No. 3: HIV/AIDS and the Right of the Child, $32^{\circ}$ periodo de sesiones, CRCl $\mathrm{GC} / 2003 / 3,2003$.

General Comment No. 2: The Role of Independent National Human Rights Institutions in the Promotion and Protection of the Rights of the Child, $32^{\circ}$ periodo de sesiones, CRC/ $\mathrm{GC} / 2002 / 2,2002$.

General Comment No. I: The Aims of Education, $26^{\circ}$ periodo de sesiones, CRC/GC/200I/I, 200I.

\section{COMITÉ DE PROTECCIÓN DE LOS DERECHOS DE TODOS LOS TRABAJADORES MIGRATORIOS Y DE SUS FAMILIARES}

\section{Committee on Migrant Workers}

$<$ http://www2.ohchr.org/english/bodies/cmw/cmw_ migrant_domestic_workers.htm>

General Comment No. I: On Migrant Domestic Workers, I $3{ }^{\text {a }}$ sesión, CMW/C/GC/I, 20 Iо.

\section{COMITÉ SOBRE LOS DERECHOS DE LAS PERSONAS CON DISCAPACIDAD}

Committee on the Rights of Persons with Disabilities

$<$ http://www.ohchr.org/EN/HRBodies/CRPD/Pages/ CRPDIndex.aspx>

Todavía no ha elaborado ninguna Observación General.

\section{COMITÉ CONTRA LAS DESAPARICIONES FORZOSAS}

Committee on Enforced Disappearances <http://www.ohchr.org/EN/HRBodies/CED/Pages/ CEDIndex.aspx>

Todavía no ha elaborado ninguna Observación General. 